\title{
Rapid Generation of Parametric Aircraft Structural Models
}

\author{
John Joe*, Viraj Gandhi ${ }^{\dagger}$ \\ Advanced Composite Structures Engineering Laboratory, \\ Purdue School of Engineering and Technology, IUPUI, Indianapolis, Indiana, 46202
}

John F. Dannenhoffer, III ${ }^{\ddagger}$

Aerospace Computational Methods Laboratory, Syracuse University, Syracuse, New York, 13244

\begin{abstract}
Hamid Dalir§
Advanced Composite Structures Engineering Laboratory, Purdue School of Engineering and Technology, IUPUI, Indianapolis, Indiana, 46202
\end{abstract}

\begin{abstract}
Within the aerospace design, analysis and optimization community, there is an increasing demand for automatic generation of parametric feature tree (build recipe) attributed multidisciplinary models. Currently, this is mainly done by creating separate models for different disciplines such as mid-surface model for aeroelasticity, outer-mold line for aerodynamics and CFD, and built-up element model for structural analysis. Since all of these models are built independently, any changes in design parameters require updates on all the models which is inefficient, time-consuming and prone to deficiencies. Here a browser-based system, called the Engineering Sketch Pad (ESP), is used. It provides the user with the ability to interact with a configuration by building and/or modifying the design parameters and feature tree that define the configuration. ESP is based an open-source constructive solid modeler, named OpenCSM, which is built upon the OpenCASCADE geometry kernel and the EGADS geometry generation system. The use of OpenCSM as part of the AFRL's CAPS project on Computational Aircraft Prototype Syntheses for automatic commercial and fighter jet models is demonstrated. The rapid generation of parametric aircraft structural models proposed and developed in this work will benefit the aerospace industry with coming up with efficient, fast and robust multidisciplinary design standardization of aircraft structures.
\end{abstract}

\footnotetext{
* Graduate Student, Department of Mechanical and Energy Engineering, AIAA Student Member.

${ }^{\dagger}$ Graduate Student, Department of Mechanical and Energy Engineering, AIAA Student Member.

${ }^{\ddagger}$ Associate Professor, Department of Mechanical and Aerospace Engineering, AIAA Associate Fellow.

$\S$ Associate Professor, Department of Mechanical and Energy Engineering, AIAA Member.
} 


\section{Nomenclature}

$\begin{array}{ll}\text { BEM } & \text { Built Up Element Model } \\ \text { BRep } & \text { Boundary Representation } \\ \text { CAD } & \text { Computer Aided Drafting, Drawing, Design, Development } \\ \text { CAPS } & \text { Computational Aircraft Prototype Syntheses } \\ \text { EGADS } & \text { Engineering Geometry Aircraft Design System } \\ \text { ESP } & \text { Engineering Sketch Pad } \\ \text { MDAO } & \text { Multi-Disciplinary Analysis andOptimization } \\ \text { MSA } & \text { Mid-Surface Aero } \\ \text { OML } & \text { Outer Mold Line } \\ \text { IML } & \text { Inner Mold Line } \\ \text { OpenCSM } & \text { Open-sourceConstructiveSolid Modeler } \\ \text { UDP } & \text { User-Defined Primitive }\end{array}$

\section{Background}

In the design, analysis and optimization of aerospace vehicles and structures, it is absolutely crucial to generate the geometry fast and in a robust way. For a given geometry, the number of structural solutions to support the design are unlimited. However, there is only one solution which could lead to the minimum weight for the structure. To realize this, a single common consistent parametric description of the design against different disciplines is necessary.

In Multi-Disciplinary Analysis and Optimization (MDAO) environments, it is a common practice to import the models from manufacturing design tools with usually IGES and STEP extensions. Although these structural parts and components are intended to be ultimately manufactured, the use of these extensions will create static (non-parametric) geometry models which are not intended for design optimization. Also to create a Boundary Representation (BRep), the models should be closed watertight which is extremely difficult due to the lack of a complete solid modeling geometry kernel to deal with the topology data if any.

A web browser based integrated software referred to as the Engineering Sketch Pad (ESP), ${ }^{1}$ is used here which completely resolves the issues mentioned above. ESP is built upon the WebViewer ${ }^{1}$ and OpenCSM$^{2}$ and is fully-parametric, attributed and is based on a feature-based solid-modeling system. OpenCSM in turn is built upon EGADS ${ }^{3}$ and OpenCASCADE. All of this software is open-source, freely available without licensing restrictions, and is in general use. ${ }^{4}$

The main objective here is to demonstrate through examples on how ESP could help the aerospace community by generation of parametric, feature-based analysis models to perform efficient MDAO. This would hopefully fill the existing gap between fully realizable $3 \mathrm{D}$ representations and conceptual design and thus can be used to an advantage throughout the preliminary and detailed design stage. 


\section{Commercial and Military Aircraft Prototype Syntheses}

Engineering Sketch Pad (ESP) is used here as the design tool to generate the structure of a commercial and a military aircraft models parametrically and create the built-up-element (BEM) ready for structural analysis. The input of ESP is written in a CSM file which is human readable and parsed by ESP. It is an ASCII file that contains all the information needed to create a model or set of sub-models.

To create an aircraft parametric model, 'despmtr' is used to create user input parameters and 'set' is used to create variables based on the inputs. These variables are mainly used to generate internal structures. In ESP if the user changes a parameter, the software will efficiently regenerate only those parts which are associated with that parameter.

ESP Master Model usually contains one or more user input design parameters. These parameters could be 1 -D single value or $\mathrm{n} \times \mathrm{n}$ Matrices. These parameters can be 'set' using 'set' command to interconnect or can directly be given by user in ESP's Graphical User Interface. They are used to input values in command arguments. Another way of using parameters is using them in if/else loop or set them as Flag.

To be able to create computational grid to be used in Computational Fluid Dynamics (CFD) or other 3D field analysis tools, the generated body has to be watertight. To ensure this, ESP uses constructive solid modelling process which guarantees the model to be realizable solids. But, for global and local structural analysis, ESP can generate non-manifold sheet bodies as thin structural plates or wire bodies. These sheet structures are necessary to generate BEM models enabling the designer to perform structural analysis using quad shell elements.

The ESP model of a military fighter aircraft with different number of ribs, spars and wing tip angles along with the associated design parameters are shown in Figure 1 and Table 1, respectively.
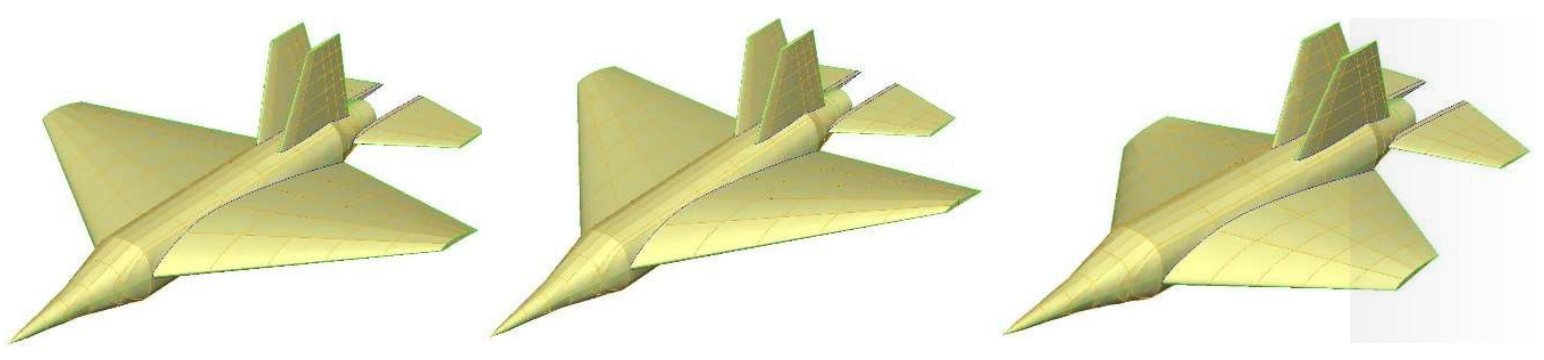

Figure 1. An ESP example of a military fighter aircraft with different number of ribs, spars and wing tip angles. 
Table 1. Design parameters used to create the geometry of the military fighter aircraft.

\begin{tabular}{|c|c|c|c|c|c|}
\hline Parametername & Value & Description & Parameter name & Value & Description \\
\hline cone_radius & 0.25 & Radius of nose cone & series_w & 4409 & NACA profile \\
\hline cone_length & 1.2 & Length of nose cone & $\mathrm{AOA} 1$ & 2.0 & $\begin{array}{l}\text { Angle of attack at } \\
\text { root }\end{array}$ \\
\hline cockpit_length & 5.5 & Length of cockpit & AOA2 & 5.0 & $\begin{array}{l}\text { Angle of attack at } \\
\text { tip }\end{array}$ \\
\hline cockpit_num & 3 & $\begin{array}{l}\text { Frame number in } \\
\text { cockpit }\end{array}$ & series_h & 406 & NACA profile \\
\hline cockpit_width & 2.0 & Width of cockpit & $\begin{array}{l}\text { hwing_start_lengt } \\
\text { h }\end{array}$ & 8.0 & $\begin{array}{l}\text { Length of } \\
\text { horizontal wing } \\
\text { at root }\end{array}$ \\
\hline engine_length & 4.5 & Length of engine & hwing_end_length & 3.0 & $\begin{array}{l}\text { Length of } \\
\text { horizontal wing } \\
\text { at tip }\end{array}$ \\
\hline engine_num & 2 & Width of engine & hwing_spars_num & 3 & $\begin{array}{l}\text { Number of spars } \\
\text { in horizontal } \\
\text { wing }\end{array}$ \\
\hline engine_width & 4.0 & $\begin{array}{l}\text { Frame number in } \\
\text { engine }\end{array}$ & hwing_tip & 36.0 & $\begin{array}{l}\text { Horizontal wing } \\
\text { tip leading edge } \\
\text { distance from } \\
\text { nose }\end{array}$ \\
\hline spars_num & 6 & Number of spars & hwing_span & 15.0 & $\begin{array}{l}\text { Span of } \\
\text { horizontal wing }\end{array}$ \\
\hline spars_initial_length & 20.0 & $\begin{array}{l}\text { Length of wing at } \\
\text { root }\end{array}$ & vwing_height & 6.0 & $\begin{array}{l}\text { Vertical wing tip } \\
\text { height from nose }\end{array}$ \\
\hline spars_final_length & 4.0 & $\begin{array}{l}\text { Length of wing at } \\
\text { tip }\end{array}$ & vwing_end_length & 3.5 & $\begin{array}{l}\text { Length of vertical } \\
\text { wing at tip }\end{array}$ \\
\hline wing_tip & 22.5 & $\begin{array}{l}\text { Wing tip leading } \\
\text { edge distance from } \\
\text { nose }\end{array}$ & vwing_tip_dist & 33.0 & $\begin{array}{l}\text { vertical wing tip } \\
\text { leading edge } \\
\text { distance from } \\
\text { nose }\end{array}$ \\
\hline wing_span & 30.0 & Span of wing & mid_ribs & 7 & $\begin{array}{l}\text { Number of ribs in } \\
\text { fuselage }\end{array}$ \\
\hline nozzle_width & 2.8 & $\begin{array}{l}\text { Initial width of } \\
\text { nozzle }\end{array}$ & wing_ribs & 5 & $\begin{array}{l}\text { Number of ribs in } \\
\text { wing }\end{array}$ \\
\hline nozzle_length & 3.0 & Length of nozzle & hwing_ribs & 2 & $\begin{array}{l}\text { Number of ribs in } \\
\text { horizontal wing }\end{array}$ \\
\hline nozzle_out_radius & 1.15 & $\begin{array}{l}\text { Radius of nozzle at } \\
\text { exit }\end{array}$ & vwing_ribs & 4 & $\begin{array}{l}\text { Number of ribs in } \\
\text { Vertical wing }\end{array}$ \\
\hline nozzle_num & 3 & $\begin{array}{l}\text { Number of frames } \\
\text { in nozzle section }\end{array}$ & & & \\
\hline
\end{tabular}


The master models in ESP are defined in terms of a feature tree and a set of design parameters. This tree depicts the sequence of the operations used to create the final design which can be extracted from the CSM file and is shown in Figure 2.

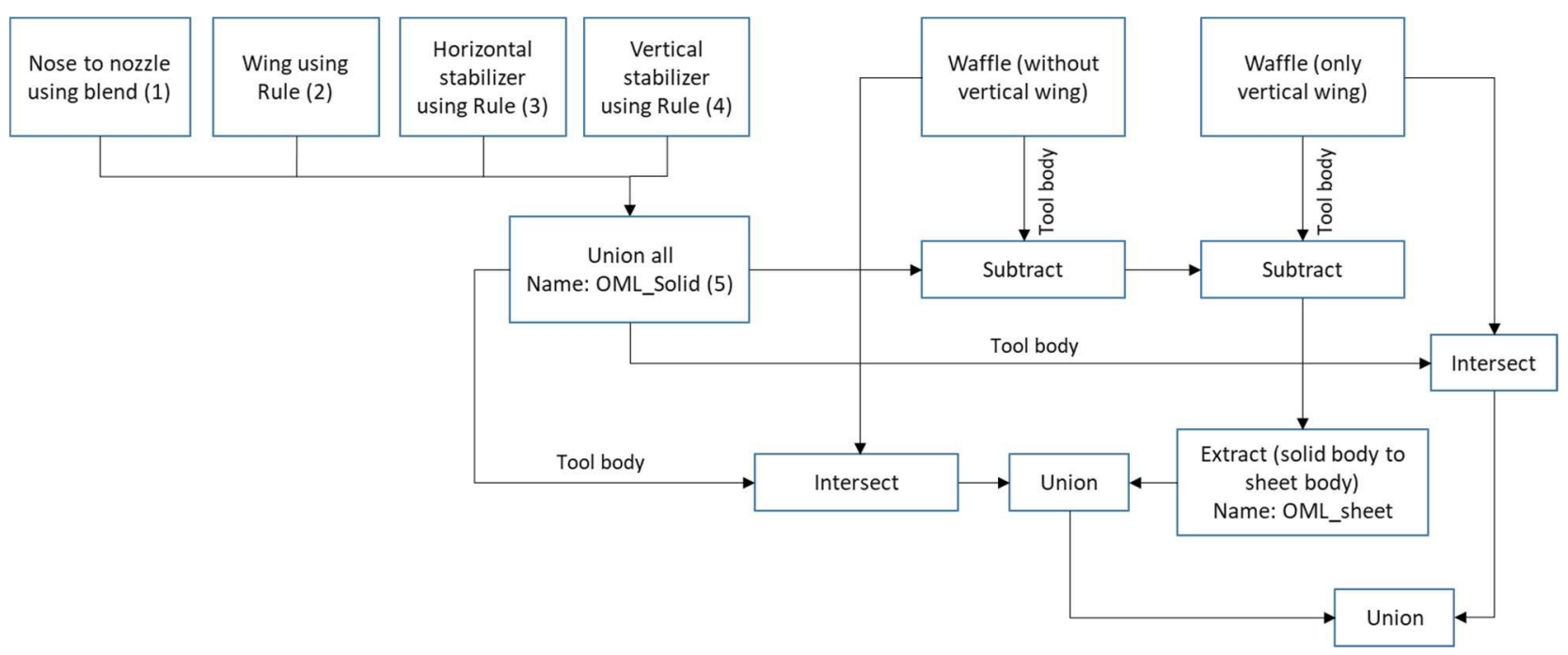

Figure 2. The ESP tree structure to generate a military fighter aircraft.

In this tree structure, each part contains of several steps. These steps are called 'Branches'. Each part starts with generation of standard primitives which includes Box, sphere, cone, cylinder, or torus. Some primitives are used to join sketches such as extrude, rule, blend, revolve, sweep, or loft. And some are User Defined Primitives (UDP) such as 'Naca' and 'supell' (super ellipse). ESP arranges bodies in a stack order approach. This means that a given command is being operated on the last generated body or the last two bodies in case of the Boolean operations.

Figure 3 shows some key steps in generation of the fighter aircraft model. Figure 3 a demonstrates the OML which is made from geometric user input parameters. Figure $3 \mathrm{~b}$ shows a parametric waffle structure which upon its intersection with the OML will generate the internal structure of the aircraft (see Figure 3c). This structure is fully parametric and one can easily and efficiently change the number, thickness and the shape of the internal structures.
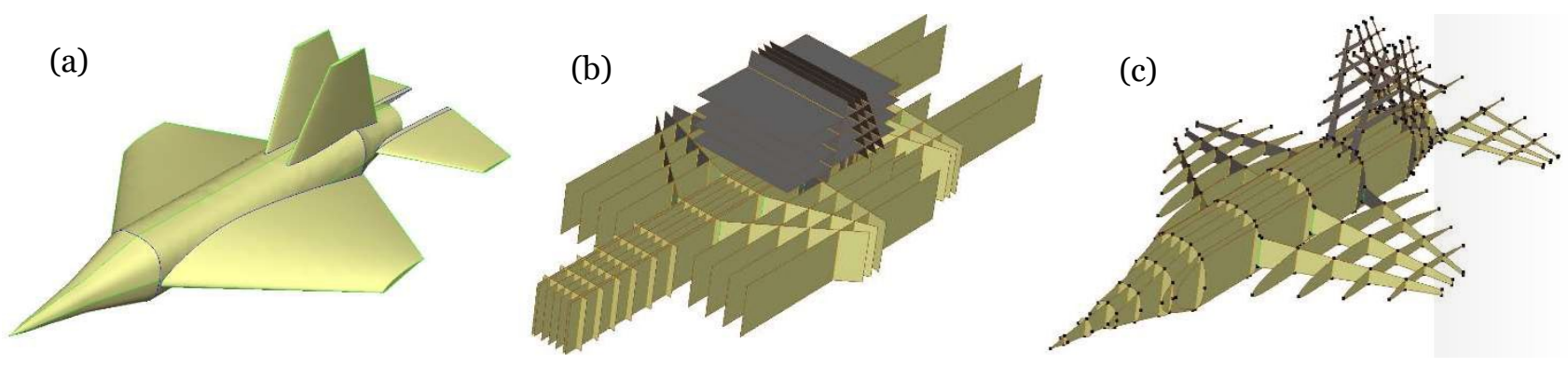

Figure 3. Parametric generation of the OML and the internal structure of a fighter plane in ESP.

The internal structure is created using Waffle UDP which takes a group of crossing lines in X-Y plane and extrudes them up in $\mathrm{Z}$ direction to create a non-manifold group of Faces. The waffle is then subtracted from the OML, which enforces the outer sheet Body to be scribed by the faces of the waffle. 
Table 2 shows the design parameters used in building the parametric model of the commercial aircraft. The three models shown in Figure 4 are different in terms of the configuration of their internal structures. The design parameters of each model have been depicted in Table 3. To create a new model with a new set of design parameters, one needs to vary the relevant design parameters. The new ESP model takes about $10-15$ minutes to regenerate which will result in a fast and accurate multidisciplinary design optimization platform.

Table 2. Design parameters used to create the geometry of the commercial aircraft

\begin{tabular}{|c|c|c|c|c|c|}
\hline $\begin{array}{c}\text { Parameter } \\
\text { name }\end{array}$ & Value & Description & $\begin{array}{c}\text { Parameter } \\
\text { name }\end{array}$ & Value & Description \\
\hline Fuse & $\begin{array}{l}{[23 \times 4]} \\
\text { matrix }\end{array}$ & $\begin{array}{l}\text { Dimensions of the } \\
\text { fuselage(x,y,z1,z2) }\end{array}$ & xroot_v & 13.2 & $\begin{array}{l}\text { Distance of root of } \\
\text { horizontal stabilizer } \\
\text { from nose }\end{array}$ \\
\hline noseList & $\begin{array}{l}{[2 \times 4]} \\
\text { matrix }\end{array}$ & $\begin{array}{l}\text { Curvature of nose } \\
\text { cone in three } \\
\text { directions }\end{array}$ & zroot_V & 0.4 & $\begin{array}{l}\text { Distance of root of } \\
\text { horizontal stabilizer } \\
\text { from central plane } \\
\text { of plane }\end{array}$ \\
\hline series_w & 4409 & $\begin{array}{c}\text { NACA profile, } \\
\text { location and } \\
\text { orientation data for } \\
\text { the wing }\end{array}$ & area_v & 9.6 & $\begin{array}{c}\text { Area of the vertical } \\
\text { tail }\end{array}$ \\
\hline wing & $\begin{array}{l}{[3 \times 5]} \\
\text { matrix }\end{array}$ & $\begin{array}{l}\mathrm{x}, \mathrm{y}, \mathrm{z} \text {, chord length \& } \\
\text { angle of attack of } 3 \\
\text { profiles in wing }\end{array}$ & taper_v & 0.3 & $\begin{array}{c}\text { Taper ratio of the } \\
\text { horizontal tail }\end{array}$ \\
\hline series_h & 406 & $\begin{array}{l}\text { NACA profile for the } \\
\text { horizontal stabilizer }\end{array}$ & aspect_v & 3 & $\begin{array}{l}\text { Aspect ratio of the } \\
\text { vertical tail }\end{array}$ \\
\hline xroot_h & 14.5 & $\begin{array}{l}\text { Distance of root of } \\
\text { horizontal stabilizer } \\
\text { from nose }\end{array}$ & sweep_v & 45 & $\begin{array}{l}\text { Swept angle of the } \\
\text { vertical tail }\end{array}$ \\
\hline zroot_h & 0.2 & $\begin{array}{l}\text { Distance of root of } \\
\text { horizontal stabilizer } \\
\text { from the central } \\
\text { plane }\end{array}$ & stringers_no & 4 & $\begin{array}{c}\text { Number of } \\
\text { stringers in one half } \\
\text { plane (this ensures } \\
\text { even number of } \\
\text { stringers) }\end{array}$ \\
\hline aroot_h & 0 & $\begin{array}{l}\text { Angle of attack of the } \\
\text { horizontal tail at the } \\
\text { tip }\end{array}$ & fore_frames_no & 6 & $\begin{array}{l}\text { Number of frames } \\
\text { between nose and } \\
\text { wing }\end{array}$ \\
\hline area_h & 0.78 & $\begin{array}{c}\text { Area of the } \\
\text { horizontal tail }\end{array}$ & aft_frames_no & 7 & $\begin{array}{l}\text { Number of frames } \\
\text { between wing and } \\
\text { vertical stabilizer }\end{array}$ \\
\hline taper_h & 0.55 & Taper ratio & ribs_no & 8 & Number of ribs \\
\hline aspect_h & $3 \cdot 7$ & $\begin{array}{l}\text { Aspect ratio of the } \\
\text { horizontal tail }\end{array}$ & iribs_no & 3 & $\begin{array}{l}\text { Number of ribs in } \\
\text { the region joining } \\
\text { the wing and } \\
\text { fuselage }\end{array}$ \\
\hline sweep_h & 25 & $\begin{array}{l}\text { Swept angle of the } \\
\text { horizontal tail }\end{array}$ & hribs_no & 6 & $\begin{array}{l}\text { Number of ribs in } \\
\text { the horizontal } \\
\text { stabilizer }\end{array}$ \\
\hline dihed_h & 3 & $\begin{array}{l}\text { Dihedral angle of the } \\
\text { horizontal tail }\end{array}$ & vribs_no & 6 & $\begin{array}{l}\text { Number of ribs in } \\
\text { the vertical } \\
\text { stabilizer }\end{array}$ \\
\hline twist_h & 2 & $\begin{array}{l}\text { Twist angle of } \\
\text { horizontal tail }\end{array}$ & spars_no & 2 & Number of spars \\
\hline series_v & 404 & $\begin{array}{l}\text { NACA profile for the } \\
\text { vertical stabilizer }\end{array}$ & & & \\
\hline
\end{tabular}


(a)

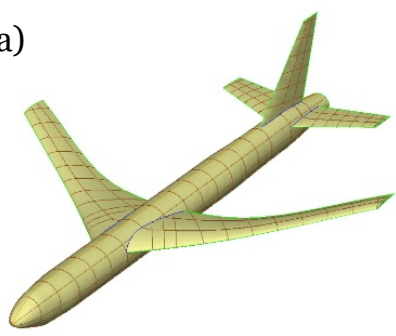

(b)

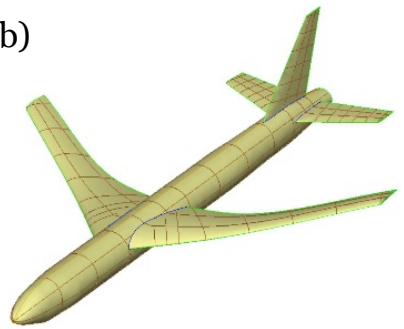

(c)

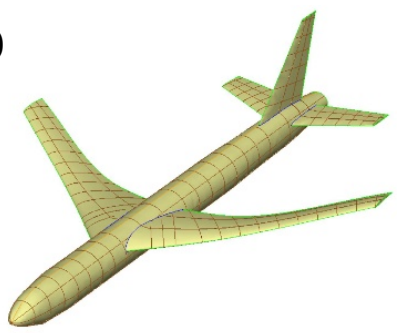

Figure 4. Parametric generation of the OML and the internal structure of a commercial plane in ESP.

Table 3. Design parameters used to generate different internal structures

\begin{tabular}{|c|c|c|c|}
\hline & $\begin{array}{c}\text { Number of ribs in } \\
\text { the wing }\end{array}$ & $\begin{array}{c}\text { Number of fore } \\
\text { frames }\end{array}$ & $\begin{array}{c}\text { Number of aft } \\
\text { frames }\end{array}$ \\
\hline Figure 4a & 8 & 6 & 7 \\
\hline Figure 4b & 5 & 3 & 4 \\
\hline Figure 4c & 10 & 8 & 8 \\
\hline
\end{tabular}

Figure 5 shows different stages of the model generation process. Figure 5 a depicts the Outer Mold Line (OML) of the aircraft which is the union of all the skins of the plane. Figure $5 \mathrm{~b}$ is an extruded waffle to generate some of the internal aircraft structure which upon its intersection with the skin OML will result in the internal structure of the plane. The waffle for the vertical tail is intersected separately with the vertical tail and then is unioned with the main waffle. Figure $5 \mathrm{c}$ shows the union of the two horizontal and vertical waffles with only the two central stringers. The remaining stringers are intersected with the fuselage, rotated and then unioned with the waffle, thus forming the final internal structure of the aircraft (see Figure $5 \mathrm{~d}$ ). The waffle structure is then subtracted from the OML to scribe it. This divides the OML into different skin panels intersected by the waffle. The scribed OML is then unioned with the internal structure and the Inner Mold Line (IML) is subtracted from the model. The resulting final model is shown in Figure 5e.

(a)

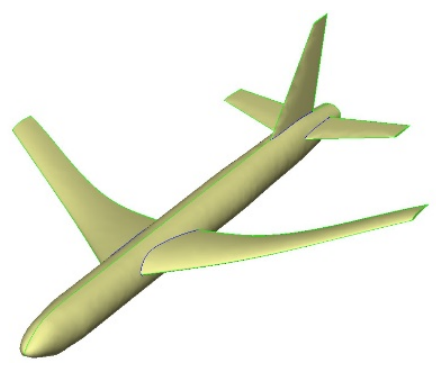

(d)

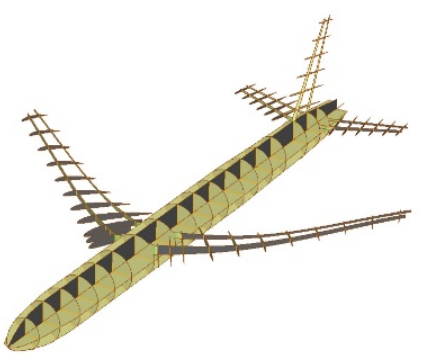

(b)

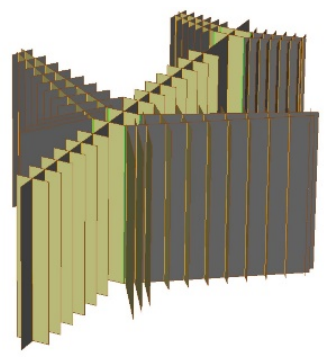

(c)

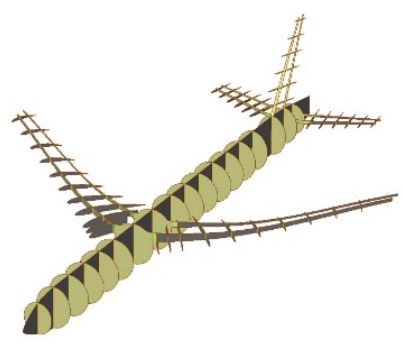

(e)

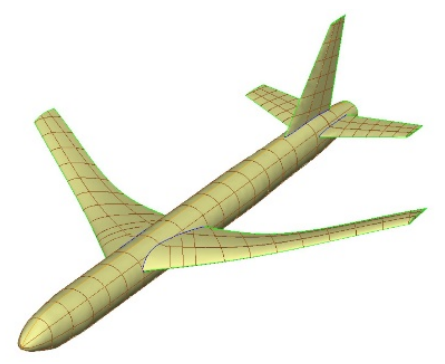

Figure 5. Parametric generation of the OML and the internal structure of a commercial plane in ESP. 


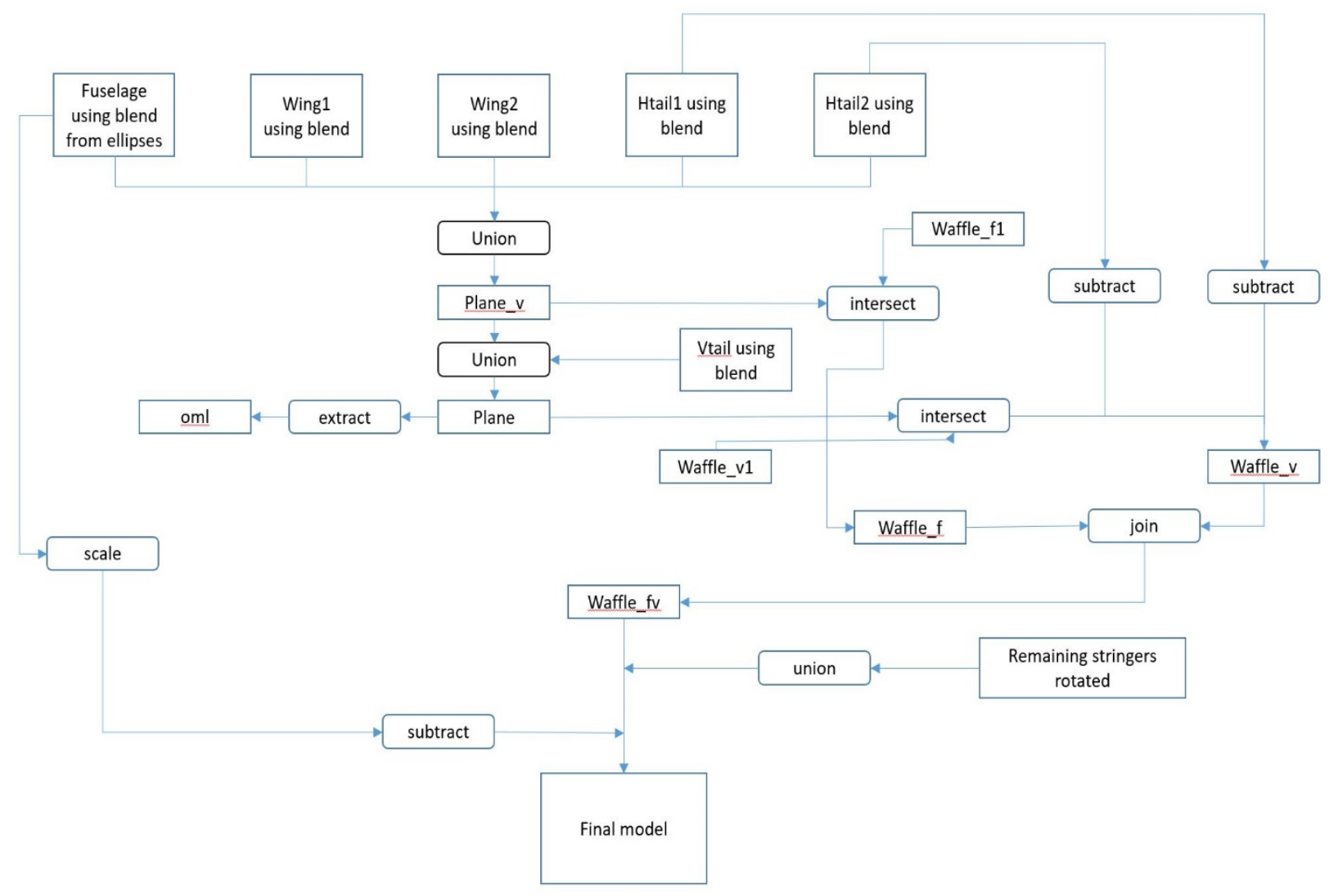

Figure 6. The ESP tree structure to generate a commercial aircraft.

The tree structure shown in Figure 6 explains the process involved in the generation of the commercial aircraft. The OML is generated by the union of the fuselage, the wing, the engine and the horizontal and vertical stabilizers, each of which are in turn generated using either the UDP blend for quadratic surface splines or UDP rule for linear surface splines from different profiles of the target solids. A parametric waffle is generated which contains the two central stringers as well as all the frames in the fuselage, the ribs and spars in the wing and the horizontal stabilizers. This waffle is intersected with the entire aircraft excluding the vertical stabilizer. A second waffle is generated that corresponds to the internal structure of just the vertical stabilizer and the frames inside the vertical tail supporting it. The result model is intersected with the vertical stabilizer. The remaining protruding parts are removed by subtracting the horizontal stabilizers from this waffle. The two waffles are unioned together to form a single body. Sheet bodies are then created and rotated, forming the remaining stringers, and are then unioned to the join of the two waffles. The OML, which is a solid body is then extracted to generate a sheet body. The waffles are subtracted from the OML to scribe the OML with the internal structure. The internal structure is then unioned with the OML to generate the final model.

In this section a more detailed design of the wing including the panel stiffeners using the parameters in Table 4 is discussed. The wing as shown in Figure 7a is modeled by creating two NACA profiles and connecting them. The internals as shown in Figure $7 \mathrm{~b}$ are created using the UDP 'waffle'. The UDP waffle allows the creation of a 2D sketch in the $\mathrm{X}-\mathrm{Y}$ plane, which is then extruded in the $\mathrm{Z}$ direction. ESP allows the waffle to be created from a detailed text file which provides control over the geometry of the waffle. Figure $7 \mathrm{c}$ shows the waffle intersected with the OML of the wing generating the internal support structure. 
Table 4. Design parameters used to create the geometry of the detailed parametric wing

\begin{tabular}{|c|c|c|}
\hline $\begin{array}{l}\text { Parameter } \\
\text { name }\end{array}$ & Value & Description \\
\hline series_w & 4409 & NACA profile of the wing \\
\hline area & 10 & area of the wing \\
\hline aspect & 6 & aspect ratio of the wing \\
\hline taper & 0.7 & taper ratio of the wing \\
\hline sweep & 20 & sweep angle of the wing \\
\hline nrib & 5 & number of ribs in the wing \\
\hline xfirst & 0.2 & $\begin{array}{l}\text { percentage distance in the } \\
\text { chordwise length of the first spar }\end{array}$ \\
\hline xlast & 0.75 & $\begin{array}{l}\text { percentage distance in the } \\
\text { chordwise length of the last spar }\end{array}$ \\
\hline nspar & 3 & number of spars in the wing \\
\hline nstiff & 3 & $\begin{array}{l}\text { number of stiffeners on the wing } \\
\text { panel }\end{array}$ \\
\hline depth & -0.01 & depth of the stiffener \\
\hline angle & 45 & $\begin{array}{l}\text { angle of the runoffs at the ends of } \\
\text { the stiffener }\end{array}$ \\
\hline
\end{tabular}

More intricate details about the wing such as the stiffeners can be modelled using the UDP stiffeners. Stiffeners are critical in the conceptual design as they are responsible for the stability of the model under buckling. UDP stiffener enables generating runoffs at both ends of the stiffeners. Figure 7 e demonstrates the entire wing with all individual panels stiffened.

\section{(a)}

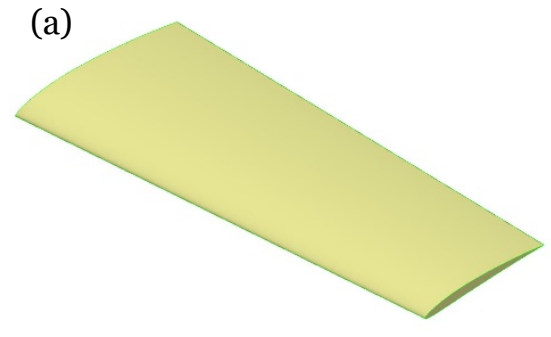

(b)

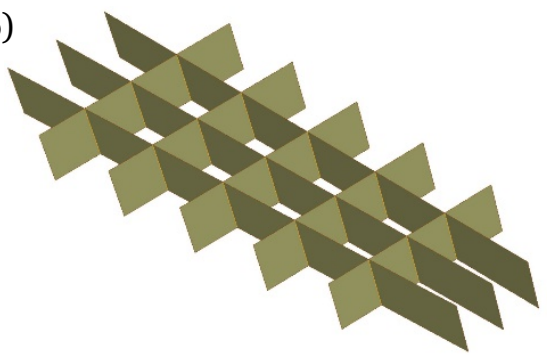

(c)

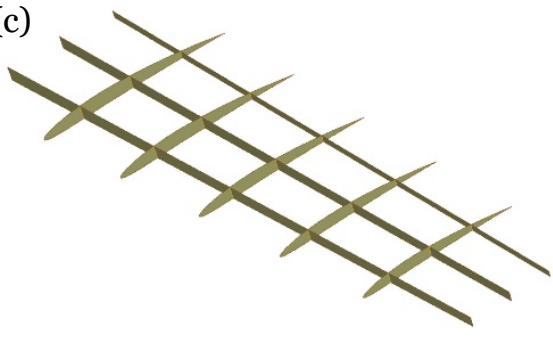

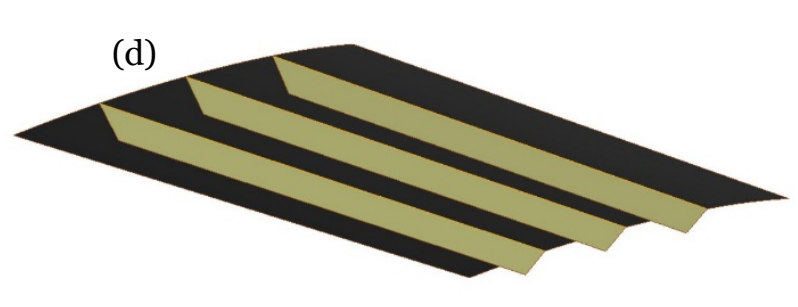

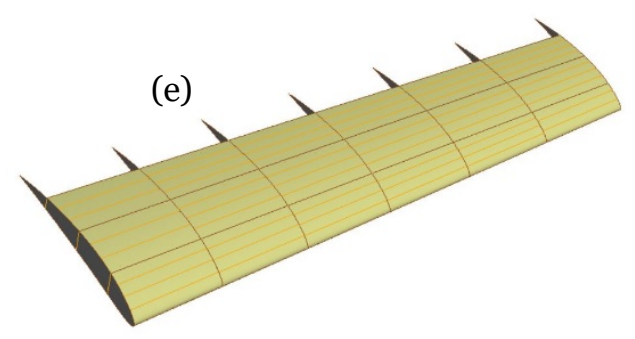

Figure 7. Parametric generation of the OML and the internal structure of a detailed wing in ESP. 


\section{Integration with the Analysis Tools}

One of the main advantages of ESP is its capability to generate BEMs which could be robustly imported by structural analysis tools such as NASTRAN. To demonstrate this, the parametric generated model of the wing of the fighter was discretized into structured quadrilateral mesh using 'createBEM' UDP in ESP (see Figure 8). This mesh structure will provide a platform for performing structural analysis.
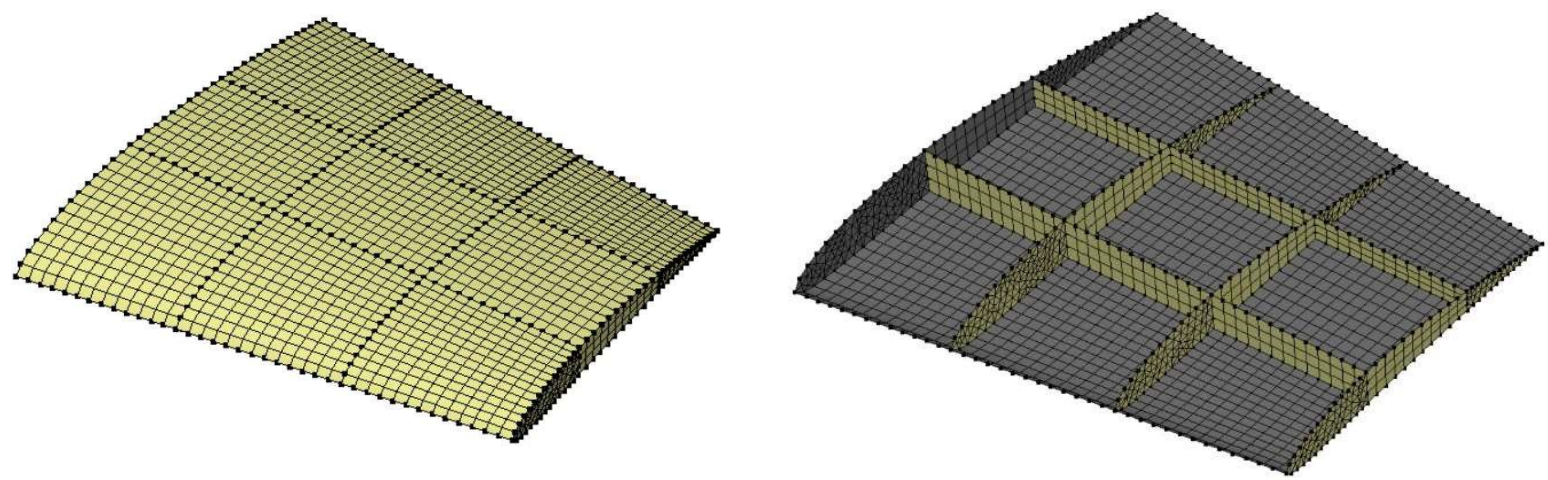

Figure 8. the parametric meshed model of the wing of the fighter in ESP.

\section{Conclusions}

The CAPS program set out with the goal of having a single source geometry capability that could provide inputs to multi-fidelity, multi-physics solvers in a quick and efficient way. We are currently working on elaborating this capability by rapid generation of commercial and military aircraft prototypes to be used in conceptual design, multi-disciplinary design optimization, and high fidelity physics simulations (notably absent is CAD assemblies and three view drawings). The main advantage is that the models are parametric, attributable and have geometric sensitivities associated with the parameters. Finally, this paper will include the steps involved in creating rapid models of two commercial and military aircrafts as well as a detailed wing where the user-intensive generation of the BEM and interface connections are automated via the CAPS infrastructure.

\section{Acknowledgement}

This work was funded by the CAPS project, which was funded under AFRL Contract FA8050-14-C-2472: "CAPS: Computational Aircraft Prototype Syntheses"; Dean Bryson is the Technical Monitor. The authors also acknowledge the discussions with Nitin Bhagat, research engineer and AFRL contractor at University of Dayton Research Institute during the formulation of various parts of these aircraft models.

\section{References}

${ }^{1}$ Haimes, R. and Dannenhoffer, J., “The Engineering Sketch Pad: A Solid-Modeling, Feature-Based, Web-Enabled System for Building Parametric Geometry," 21 st AIAA Computational Fluid Dynamics Conference, No. 2013-3073, American Institute of Aeronautics and Astronautics, Jun. 2013.

${ }^{2}$ Dannenhoffer, J., "OpenCSM: An Open-Source Constructive Solid Modeler for MDAO," 51st AIAA Aerospace Sciences Meeting including the New Horizons Forum and Aerospace Exposition, No. 2013-0701, American Institute of Aeronautics and Astronautics, Jan. 2013.

${ }^{3}$ Haimes, R. and Drela, M., "On The Construction of Aircraft Conceptual Geometry for High-Fidelity Analysis and Design," 50th AIAA Aerospace Sciences Meeting including the New Horizons Forum and Aerospace Exposition, No. 20120683, American Institute of Aeronautics and Astronautics, Jan. 2012.

${ }^{4}$ Bhagat, N. D. and Alyanak, E. J., "Computational Geometry for Multi-fidelity and Multi-disciplinary Analysis and Optimization," 52nd Aerospace Sciences Meeting, No. 2014-0188, American Institute of Aeronautics and Astronautics, Jan. 2014. 